\begin{tabular}{|c|c|c|}
\hline \hline & International Journal of Current Research in \\
\hline & Biosciences and Plant Biology \\
\hline PUCELLENT \\
PUBLISHERS
\end{tabular}

\title{
Toxicology studies and antibacterial activities of the ethyl acetate extract of Piliostigma reticulatum
}

\author{
A. O. Daniel ${ }^{*}$, T. Temikotan ${ }^{2}$, K. Fadairo ${ }^{2}$, and D. A. Ibiyemi3 \\ ${ }^{1}$ Department of Biological Sciences, Achievers University, Owo, Ondo State, Nigeria \\ ${ }_{2}^{2}$ Department of Medical Laboratory Sciences, Achievers University, Owo, Ondo State, Nigeria \\ 3Department of Chemical Sciences, Achievers University, Owo, Ondo State, Nigeria \\ *Corresponding author; e-mail: toyosidanny@yahoo.com
}

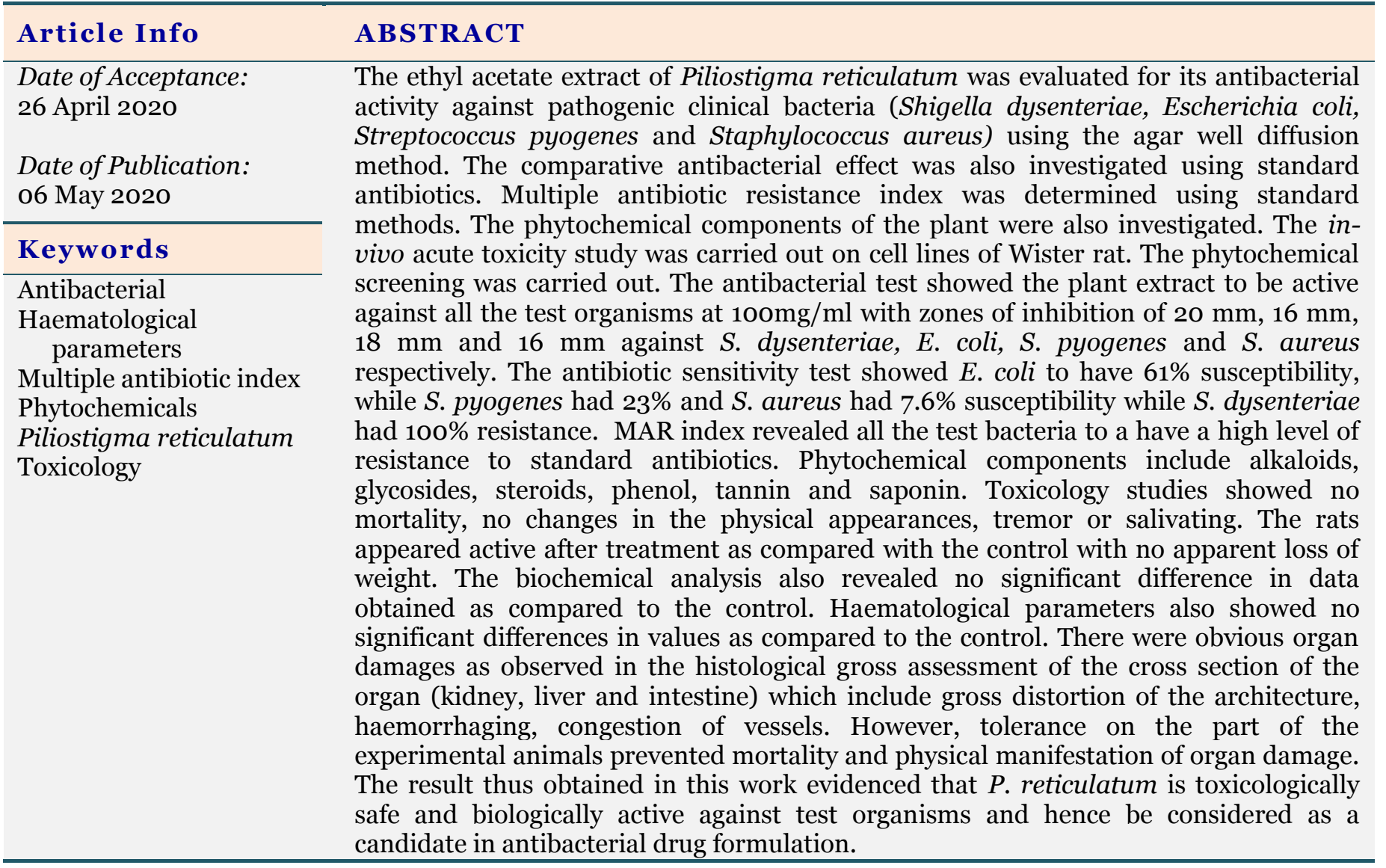




\section{Introduction}

The need for new antimicrobial is an urgent need of the time in light of significant toxicities and the emergence of resistant bacteria to antibiotics. The use of plants in the treatment of infections is as old as man. Medicinal plants are used all over the world for the prevention and treatment of diseases (De-an et al., 2015). In recent times, more focus has been on identifying the active components of medicinal plants and the possible mechanism of action of the biological components. Many researchers have worked on essential oils in medicinal plants with varying results but same conclusion that essential oils are responsible for the plant's biological activity.

Essential oils and extracts of various species of edible and medicinal plants consist of very potent natural biologically active agents (Nychas et al., 2003). Essential oils contain a variety of volatile molecules such as terpenes and phenol-derived aromatic and aliphatic components.

The medicinal values of plant depend chiefly on the secondary metabolites present in them which produce psychological effects on the human body (Bastos et al., 2009). In spite of the successes recorded in the use of medicinal plants in the treatment of infections, the problem of safety in herbal remedies continues to be a major concern. The perception that herbal medicine is safe and devoid of side effects remains a misconception. Herbs have been recorded to produce a wide range of undesirable or adverse side effects some of which can cause severe injuries, abortion, abdominal pains, liver problems, dizziness, ulcer, loss of appetite and even death (Artanti et al., 2012). Due to the above fact, this study is carried out to investigate the phytochemicals present in and the toxicity of Piliostigma reticulatum

\section{Materials and methods}

\section{Sampling and preparation of plant material}

Fresh stem bark of Piliostigma reticulatum was sampled in the early hours of the morning and transported to the laboratory for cleaning, preparation and drying. The dried sample was pulverized into powder and subjected to extraction procedure using ethyl acetate.

\section{Collection and maintenance of test Bacteria}

Clinical strains of Shigella dysenteriae, Escherichia coli, Streptococcus pyogenes and Staphylococcus aureus were collected on agar slant from the Microbiology Department of Obafemi Awolowo University, Ile-Ife , Osun State, Nigeria and maintained by constant sub-culturing until use.

\section{Evaluation of the antibacterial activity of plant extract}

A one (1) gram amount of the plant extract was reconstituted in 10mls of Dimethyl sulfoxide (DMSO). The agar well diffusion method of Perez, (1990) was adopted for the antimicrobial assay. Test organisms were suspended in Nutrient broth and incubated for 4 hours to obtain a concentration corresponding to MacFarlands constant (0.5 X $\left.10^{8} \mathrm{cfu} / \mathrm{ml}\right)$. The sterile Petri-dishes were inoculated by pour plate method. Serial dilution of the plant extract using sterile distilled water was carried out to obtain concentrations of $80 \mathrm{mg} / \mathrm{ml}$, $60 \mathrm{mg} / \mathrm{ml}, 40 \mathrm{mg} / \mathrm{ml}, 20 \mathrm{mg} / \mathrm{ml}$ and $10 \mathrm{mg} / \mathrm{ml}$. About $1 \mathrm{ml}$ amount of the test organisms was dispensed aseptically into each Petri dish and about $20 \mathrm{ml}$ of sterilized nutrient agar was poured into sterile Petri dish. The agar plates were allowed to set in the plates. Wells of about $6 \mathrm{~mm}$ were punched over the agar plates equidistant from each other using sterile gel cork borer and about $0.5 \mathrm{ml}$ of each plant extracts of different concentrations as prepared by the serial dilution were added to the wells using a micropipette. The extracts were allowed to diffuse into the agar for about 20mins after which the plates were incubated for $24 \mathrm{~h}$ at $37^{\circ} \mathrm{C}$. After incubation the diameter of inhibitory zones formed around each wells were measured in $\mathrm{mm}$ and recorded. Experiments were carried out in triplicates and the average values recorded.

\section{MIC of plant extract}

A modified method of Weigand et al. (2008) was adopted in the determination of MIC. The MIC of the extracts was determined by diluting the various concentrations with nutrient broth. $1 \mathrm{ml}$ of a serial dilution of $100 \mathrm{mg} / \mathrm{ml}, 80 \mathrm{mg} / \mathrm{ml}, 60 \mathrm{mg} / \mathrm{ml}, 40$ $\mathrm{mg} / \mathrm{ml}, 20 \mathrm{mg} / \mathrm{ml}$ and $10 \mathrm{mg} / \mathrm{ml}$ of the extracts were added to test tubes containing nutrient broth were mixed in the test tube. Specifically $0.1 \mathrm{ml}$ of 
standardized inoculum of $0.5 \times 10^{8} \mathrm{cfu} / \mathrm{ml}$ was added to each tube. The tubes were incubated aerobically at $37^{\circ} \mathrm{C}$ for $18-24 \mathrm{hrs}$. Two control tubes were maintained for each test batch. This is as follows: tube containing extracts and the growth medium without inoculums (antibiotic control) and the tube containing the growth medium and the inoculums (organism control). MIC was determined as the lowest concentration of the extracts permitting no visible growth (no turbidity) when compared with the control tubes.

\section{MAR (Multiple antibiotic resistance) index}

The MAR was determined according to the procedure of Krumperman (1983).

\section{Phytochemical screening}

The plant was screened quantitatively and qualitatively for phytochemicals using the methods of Trease and Evans (2002) and Odebiyi and Sofowora (1993).

\section{Determination of the acute toxicity of plant extract}

The acute oral toxicity extract of Piliostigma reticulatum was evaluated in rat according to the procedures outlined by the Organization for Economic Co-operation and Development (OECD) (OECD, 1995). Different doses of between 313 $\mathrm{mg} / \mathrm{kg}$ and $5000 \mathrm{mg} / \mathrm{kg}$ of crude extract were administered to rats in the treatment groups by the oral route using oral gavage. The crude extract was suspended in a vehicle (distilled water). Following the fasting period, body weight of the rats were determined and the dose was calculated in reference to the body weight as the volume of the extracts solution given to the rats is $0.05 \mathrm{ml} / \mathrm{kg}$.

Other rats were allotted distilled water and were regarded as the control groups. Food was provided to the rats approximately an hour after treatment. The rats were observed in detail for any indications of toxicity effect within the first six hours after the treatment period, and daily further for a period of 14 days. Surviving animals were weighed and visual observations for mortality, behavioral pattern, changes in physical appearance, injury, pain and signs of illness were conducted daily during the period.

\section{Signs recorded during acute toxicity studies}

Direct observation parameters include touch response, salivation, pupil dilation, nervousness, tremor, and fatigue and skin color.

\section{Experimental animals' observation throughout the period of study}

(i) Body Weight: Weight of each rats were recorded on day $\mathrm{O}$ to day 14 .

(ii) Clinical signs: All animals were observed daily for clinical signs or symptoms.

(ii) Mortality: All animals were observed twice daily for mortality during entire study period.

\section{Biochemical parameters analyzed}

Biochemical parameters were performed in serum. Serum glutamic oxaloacetic transaminase (SGOT), serum gluatamic pyruvic transaminase activities (SGPT), serum levels of alkaline phosphotase (ALP), cholesterol, differential leukocyte count (DLC), neutrophils, lymphocytes, eosinophils, basophils, reticulocytes, platelets, hemoglobin level and hematocrit values were determined using the manufacturer's test kit (Gribble's Lab, Penang, Malaysia). For clinical biochemistry tests, triglycerides, total protein and total albumin levels were estimated.

\section{Histological examination of liver}

At the end of treatment, animals were sacrificed and liver were collected for histological examinations. The organs were immediately fixed in $10 \%$ formalin and processed for histology with H\&E staining.

\section{Hematological and biochemical assessment}

Blood samples of extract treated and control groups were drawn from the jugular and $5 \mathrm{ml}$ of blood was collected into EDTA tubes for hematological parameters and $5 \mathrm{ml}$ in heparin tubes for clinical biochemistry tests according to the procedure of Ogbu and Okechukwu (2001). For hematological testing, red blood cell (RBC), white blood cell (WBC) count, calcium, inorganic phosphate were analyzed using the manufacturer's 
test kit (Gribble's Lab, Penang, Malaysia) total protein, alanine aminotransferase (ALT), aspartate aminotransferase (ALT), alkaline phosphatase using the modified method of Ode et al. (2017), The results are expressed as mean \pm standard error of the mean (SEM).

\section{Ethical consideration}

The study was conducted after having approval from the Ethical and Scientific committee of the Faculty of Science, Ekiti State University, Ado Ekiti, Ekiti State, Nigeria and in line with the highest standard for the humane and compassionate use of animals according to the Committee on Guidelines for the Use of Animals in Neuroscience and Behavioral Research. 2003.

Animals used in this study were not subjected to any unnecessary painful and terrifying situations (OECD, 1995). To keep the pain and suffering minimal during any surgical intervention all animals were given chloroform anesthetic and the procedure was carried out by a well-trained person. The animals were protected from pathogens and placed in appropriate environment. The numbers of animals were reduced to the minimum possible that allows investigators achieving the scientific objectives of the study (OECD, 1995).

\section{Statistical analyses}

One-way analysis of variance (ANOVA) was employed for between and within group comparison while student's t-test was used for paired comparison. 95\% level of significance ( $\mathrm{p} \leq 0.05)$ was used for the statistical analysis.

\section{Histomorphologic examination}

The samples of liver collected were fixed in form a saline for 24 hours. The liver of the test animals were excised and observed grossly and were processed histologically using automatic tissue processor (Hestion-ATP700o tissue processor Germany). Sections of the tissues were obtained using digital rotary microtome (Hestion ERM 4000 Germany). Staining of the section was according to Mayer's Haematoxylin and Eosin staining technique for examination by light microscopy (Bancroft and Marilyn, 2002).

\section{Microscopy and Photomicrography}

The sections of the organ were examined using Swift (R) Binocular Microscope with an in built lighting system and white films with an Olympus photomicroscope (R) (Opticshot -2; Nikon, Tokyo, Japan) at X40 magnification.

\section{Results}

The antibacterial activity of the plant extract was compared with standard antibiotics and the results are presented in Table 1 . The plant extract was active against the test bacteria with zones of inhibition ranging from $20 \mathrm{~mm}$ against $S$. dysenteriae, $16 \mathrm{~mm}$ against $E$. coli, $18 \mathrm{~mm}$ against $S$. pyogenes and $16 \mathrm{~mm}$ against $S$. aureus. The comparative antibiotic test using antibiotic disks showed $S$. dysenteriae to be resistant to all antibiotic disks, $E$. coli was resistant to ciprofloxacin, augmentin, nitrofurantoin, tetracycline and ceftriazone. $S$. pyogenes was sensitive to gentamycin, chloramphenicol, cotrimoxazole, and nitrofurantoin while $S$. aureus was sensitive to gentamycin only.

Table 1. Comparative antibacterial effect of plant extract and standard antibiotics.

\begin{tabular}{|c|c|c|c|c|c|c|c|c|c|c|c|c|c|c|}
\hline \multirow{3}{*}{ Test Organisms } & \multicolumn{14}{|c|}{ Zone of inhibition in $\mathbf{~ m m}$} \\
\hline & \multirow{2}{*}{$\begin{array}{l}\text { Plant } \\
\text { extract }\end{array}$} & \multicolumn{2}{|c|}{ Antibiotics } & \multirow[b]{2}{*}{ OFL } & \multirow[b]{2}{*}{ STR } & \multirow[b]{2}{*}{$\begin{array}{l}\text { CH } \\
\mathbf{L} \\
\end{array}$} & \multirow[b]{2}{*}{ CRO } & \multirow[b]{2}{*}{ GEN } & \multirow[b]{2}{*}{ PFX } & \multirow[b]{2}{*}{ COT } & \multirow[b]{2}{*}{ CPX } & \multirow[b]{2}{*}{ AUG } & \multirow[b]{2}{*}{ NIT } & \multirow[b]{2}{*}{ TET } \\
\hline & & ERY & AMX & & & & & & & & & & & \\
\hline Shigella dysenteriae & 20 & - & - & - & - & - & - & - & - & - & - & - & - & - \\
\hline Escherichia coli & 16 & 20 & 14 & 24 & 12 & 24 & - & 30 & 24 & 22 & - & - & - & - \\
\hline Streptococcus pyogenes & 18 & - & - & - & - & 28 & - & 28 & - & 14 & - & - & 14 & - \\
\hline
\end{tabular}




\section{MAR (Multiple antibiotic resistance) Index}

The multiple resistant factor of the bacteria strain is presented in Table 2. All the test organisms were resistant to more than three antibiotics showing a high MAR index. The MAR index of $S$. dysenteriae was 1.o, E. coli was $0.39, S$. pyogenes was 0.69 and S. aureus was 0.92 .

Table 2: MAR (Multiple antibiotic resistance) index of the test organisms.

\begin{tabular}{ll}
\hline Test organisms & MAR index \\
\hline Shigella dysenteriae & 1 \\
Escherichia coli & 0.39 \\
Streptococcus pyogenes & 0.69 \\
Staphylococcus aureus & 0.92 \\
\hline
\end{tabular}

The results presented in Tables 1 and 2 showed that the plant extracts has more antibacterial activities over standard antibiotics.

\section{Minimum inhibitory concentration (MIC) of plant extract}

The MIC of the plant extract ranged from $20 \mathrm{mg} / \mathrm{ml}$ to $100 \mathrm{mg} / \mathrm{ml}$. The result is as presented in Fig. 1.

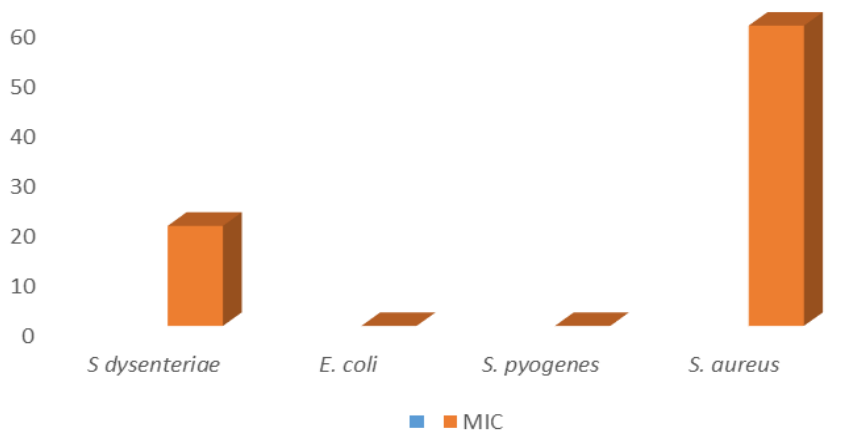

Fig. 1: Minimum inhibitory concentration (MIC) of plant extract against test organisms.

\section{Phytochemical screening}

The phytochemicals discovered in Piliostigma reticulatum include alkaloids, glycosides, steroids, phenol, tannin and saponin.

\section{Physical observation and mortality of experimental animals}

The present study conducted according to the OECD guidelines 423 revealed that the extracts did not produce any mortality throughout the study period of 14 days even when the limit dose was maintained between $313 \mathrm{mg} / \mathrm{kg}$ and $5000 \mathrm{mg} / \mathrm{kg}$ of body weight. So, testing the extracts at a maximum dose was practically non-toxic. Table 3 indicates the direct parameters observed before and after the administration of the test substance for the two different plants.

The results showed no adverse changes in physical parameters throughout the dosing period. There was no significant change in the mean body weight of the animals in treated groups as compared to treated control group at the end of treatment. No abnormality was observed when the behaviour of rats treated with plant extracts compared with control group. There was no significant difference in the initial and final weights between the control and treated rats $(\mathrm{P}>0.05)$. There were no mortalities recorded in animals treated with a single dose of $5000 \mathrm{mg} / \mathrm{kg}$ body weight showing that the test animals have a high tolerance for the plant extract. Therefore, the approximate lethal dose (LD5O) of the extracts in the experimental rats was higher than $5000 \mathrm{mg} / \mathrm{kg}$.

The effects of extracts on the percentage increase in body weight of the control and treated rats are shown in Table 4. Generally, a steady increase in the body weight was observed in all the treated rats compared with control up to the $1^{\text {st }}$ week.

\section{Biochemical analysis results of blood samples of experimental animals}

Table 4 shows the results of the effects of extracts on the serum biochemical parameters. There was a significant increase $(\mathrm{P} \leq 0.05)$ in the activities of Alanine amino transferase (ALT) in animals treated with high dose of plant extracts. At $2,500 \mathrm{mg} / \mathrm{kg}$ the result was $48.25 \pm 1.8$ and at $5000 \mathrm{mg} / \mathrm{kg}$, the ALT level was $68.14 \pm 12$ which were a great deviation from the values recorded for the control (without treatment).

Aspartate amino transferase increased in the treated rats when compared with the control. The increase was gradual until a high value of $152.5 \pm 0.2$ was attained at the $5000 \mathrm{mg} / \mathrm{kg}$ extract. However, the difference between the values of the control and treated animals were not significant ( $\mathrm{P}>0.05)$. Alkaline phosphatase (ALP) showed no 
significant difference $(\mathrm{P}>0.05)$ increase in rats treated with extracts when compared with the control. There were also no significant ( $\mathrm{P}>0.05)$ changes in, total protein, cholesterol, triglycerides and creatinine of the treated groups compared with control.

Table 3. Physical observation and mortality of experimental animals.

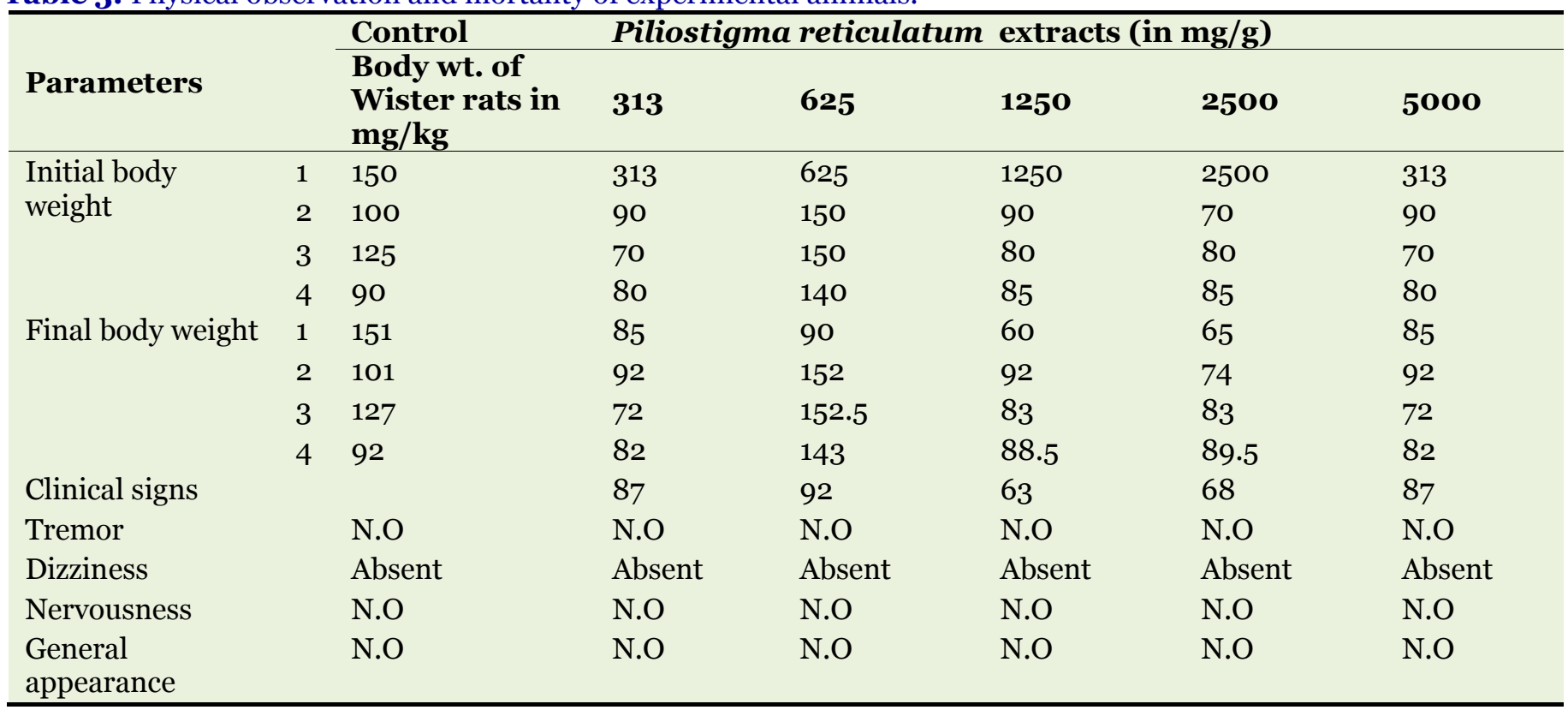

Table 4. Biochemical parameters of the serum of Wister rat dosed with plant extract.

\begin{tabular}{lllllll}
\hline \multirow{2}{*}{ Parameters } & \multirow{2}{*}{ Control } & \multicolumn{5}{c}{ Piliostigma reticulatum (Dose mg/kg body weight) } \\
\cline { 3 - 7 } & & $\mathbf{3 1 3}$ & $\mathbf{6 2 5}$ & $\mathbf{1 2 5 0}$ & $\mathbf{2 5 0 0}$ & $\mathbf{5 0 0 0}$ \\
\hline ALT & $41.00 \pm 8.0$ & $41.00 \pm 8$ & $36.38 \pm 2$ & $42.18 \pm 5$ & $48.25 \pm 1.8$ & $68.14 \pm 12.0$ \\
AST & $101.4 \pm 0.4$ & $122 \pm 0.5$ & $146 \pm 0.2$ & $135 \pm 0.5$ & $143 \pm 0.4$ & $152.5 \pm 0.2$ \\
ALP & $62.6 \pm 0.5$ & $65 \pm 0.2$ & $70.1 \pm 0.2$ & $72 \pm 0.5$ & $74.1 \pm 0.5$ & $79.7 \pm 0.2$ \\
Total protein $(\mathrm{g} / \mathrm{dl})$ & $7.23 \pm 0.5$ & $7.08 \pm 0.2$ & $7.38 \pm 0.3$ & $7.12 \pm 0.5$ & $7.22 \pm 0.8$ & $7.48 \pm 0.2$ \\
Cholesterol $(\mathrm{mg} / \mathrm{l})$ & $144 \pm 0.36$ & $115.0 \pm 0.2$ & $118 \pm 0.2$ & $113.9 \pm 0.4$ & $124 \pm 0.4$ & $108 \pm 0.2$ \\
Triglycerides $(\mathrm{mMol} / \mathrm{l})$ & $129.4 \pm 0.5$ & $128 \pm 0.2$ & $133 \pm 0.2$ & $139 \pm 0.2$ & $147.8 \pm 0.2$ & $156 \pm 0.2$ \\
Creatinine $(\mu \mathrm{Mol} / \mathrm{L})$ & $45.80 \pm 12$ & $48.2 \pm 1.28$ & $50.0 \pm 1.5$ & $54.75 \pm 1.28$ & $52.75 \pm 2.43$ & $54.80 \pm 0.2$ \\
\hline
\end{tabular}

Legend: ALT $=$ Alanine amino transferase, AST $=$ Aspartate amino transferase, ALP $=$ Alkaline phosphatase

Haematological parameters of Wister rats treated with plant extract

The serum collected from sacrificed Wister rats showed results as presented in Table 5. The heamoglobin (HB) was in the control rat $14.25 \pm 0.21$, A sudden increase was observed at the dose of $313 \mathrm{mg} / \mathrm{g}$, however, the values stabilized and at $5000 \mathrm{mg} / \mathrm{g}, 15.85 \pm 0.5$ was recorded. There was no significant increase or decrease in heamoglobin in treated rats after treatment with plant extract.
There was also no significant difference in the percentage PVC in the control and treated rat. Similarly, there was no significant difference in the WBC, platelets, neutrophils, lymphocytes and monocytes in the control and treated rats.

\section{Histopathology of harvested organs from treated rats}

\section{Observation of the liver section}

In the liver section, there was relatively mild portal 
congestion and dilatation of the central vein in the liver sections from the treated group $(5000 \mathrm{mg} / \mathrm{kg}$ ) compared with the control section of the liver. However, 2500 and 5000 revealed intense distortion in the hepatic architecture. The hepatic cells intralobular veins and the endothelium were found to have shrunk in the two concentrations. Histopathology findings in the treated groups (1 and 2) were in keeping with normal histology of organs when compared to the control group (Plate 1) without evidence of necrosis but with mild deleterious effect at the cellular level which was observed to be dose related offences.

\section{Observation of the liver section}

The result (H\&E) revealed that administration of $P$. reticulatum caused varying degree of cytoarchitectural distortion and vasculogenic effect on the kidney which affected blood vessels, haemorrhagic and chronic inflammatory cells appearing in the treatment groups compared to the control group (Plate 2a). Narrowing of the lumen also occurred with associated hypertrophic blood vessels and haemorrhage extending into the interstitium. There were several diffuse degeneration and necrosis of the tubular epithelial cells in the kidneys of the treated animals (2500$5000 \mathrm{mg} / \mathrm{kg}$ ). The degenerative and atrophic changes where observed more in the kidneys of rats that received the higher dose $(5000 \mathrm{mg} / \mathrm{kg})$ of $P$. reticulatum. It may be inferred from the present results that higher doses of $P$. reticulatum may have resulted in degenerative and atrophic changes observed in the renal corpuscle.

\section{Intestinal plates of different concentrations of Piliostigma reticulatum}

Histomorphometrical findings of the control group revealed normal intestinal mucosa characterized by tall villi with equal thickness and normal crypt (Plate 3a). Treated rats in groups $2(625 \mathrm{mg} / \mathrm{kg})$ also showed normal intestinal mucosa. Treated groups $3(1250 \mathrm{mg} / \mathrm{kg})$ showed less severe lesions as compared to treated groups 4 and 5 . The plates presented on Plate 3c, 3d and $3 \mathrm{e}$ showed an intense inflammation, atrophy and distortion of the villi. The mucosa layers were destroyed due to intense mononuclear cells inflammatory infilterates in the mucosa and submucosa layers. The histopathology of the liver after treatment that $P$. reticulatum at high concentration caused congestion in the centrolobular veins and this symptom could be attributed to a congestion focus in the sinusoid capillary, hydropic degeneartion and portal/ periportal oedema formation (Plate $3 \mathrm{~d}$ and 3e). The damages observed in the histopathological result showed serious injury to the intestinal villi.

Table 5. Haematological test results of blood sampled from experimental animals.

\begin{tabular}{|c|c|c|c|c|c|c|}
\hline \multirow{2}{*}{ Parameters } & \multicolumn{6}{|c|}{ Piliostigma reticulatum (Dose (mg/g body weight) } \\
\hline & Control & 313 & 625 & 1250 & $\mathbf{2 5 0 0}$ & 5000 \\
\hline $\mathrm{HB}(\mathrm{mg} / \mathrm{dl}$ & $14.25 \pm 0.21$ & $15.60 \pm 0.3$ & $16.0 . \pm 0.5$ & $15 \cdot 78 \pm 0.6$ & $15 \cdot 74 \pm 0.58$ & $15.85 \pm 0.5$ \\
\hline PCV (\%) & $41.50 \pm 2.1$ & $40.6 \pm 1.4$ & $40.4 \pm 0.5$ & $41.0 \pm 1.1$ & $43.7 \pm 0.5$ & $45 \pm 0.5$ \\
\hline 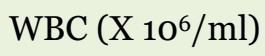 & $6.15 \pm 1.63$ & $6.92 \pm 1$ & $6.56 \pm 0$ & $7.26 \pm 1$ & $7.88 \pm 0.5$ & $7.68 \pm 1$ \\
\hline Plts $\left(\mathrm{x} 10^{3} / \mu \mathrm{L}\right)$ & $561.00 \pm 73$ & $605 \pm 23.59$ & $640 \pm 56$ & $891.40 \pm 37$ & $878.80 \pm 80$ & 850.60 \\
\hline Neu (\%) & $20.00 \pm 1.41$ & $25.2 \pm 0.5$ & $26 \pm 0.5$ & $31 \pm 0.5$ & $39 \pm 0.9$ & $38 \pm 0.6$ \\
\hline Lym (\%) & $70.50 \pm 3.54$ & $67.8 \pm 8.3$ & $71.6 \pm 2.4$ & $70.1 \pm 1.9$ & $73.6 \pm 0.6$ & $72.8 \pm 8.3$ \\
\hline Mon (\% & $8.50 \pm 2.12$ & $8.0 \pm 0.6$ & $8.3 \pm 0.3$ & $7.80 \pm 0.2$ & $8.18 \pm 0.6$ & $8.40 \pm 0.5$ \\
\hline
\end{tabular}

Key:

$\mathrm{HB}=$ Heamoglobin

PCV $=$ Packed cell volume

$\mathrm{WBC}=$ White blood cells

Plts = Platelets

$\mathrm{Neu}=$ neutrophils

Lym $=$ Lymphocytes

Mon $=$ Monocytes 


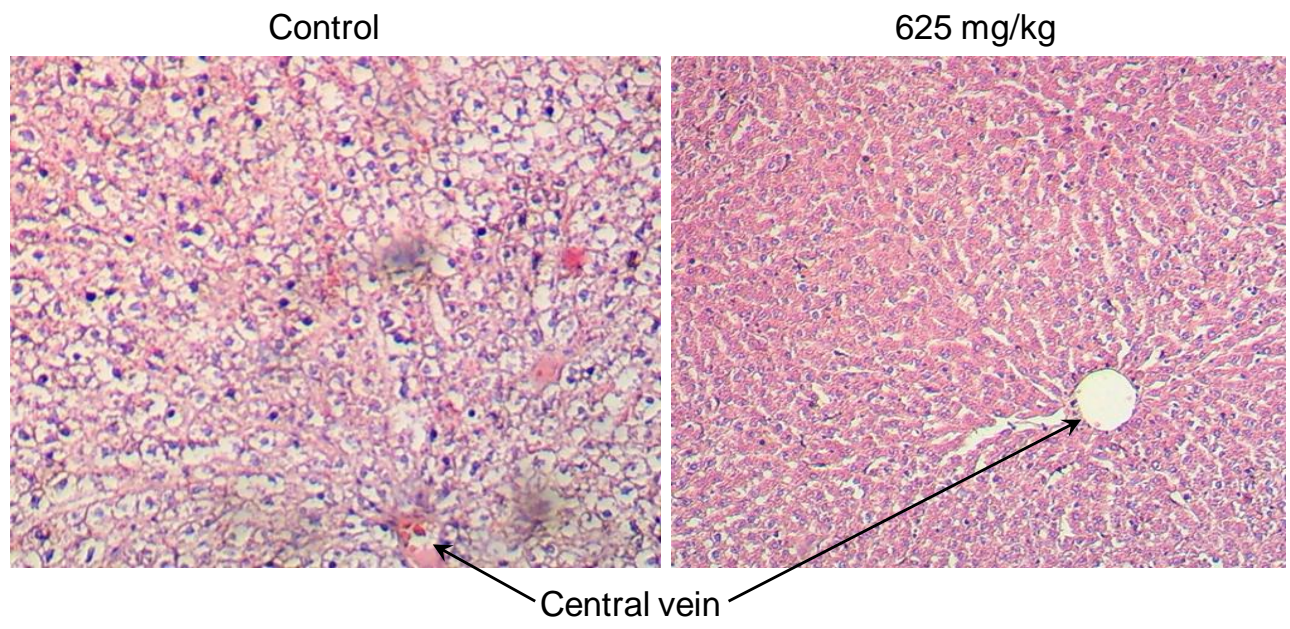

Plate 1a. A photo micrograph of a liver section of a rat in the control group showing: normal central vein, norma arrangement in of liver cords. The hepatocytes are seen radiating from the central vein and separated from each other by normal irregular blood sinusoids (H \& E. × 400).

\section{$1250 \mathrm{mg} / \mathrm{kg}$}

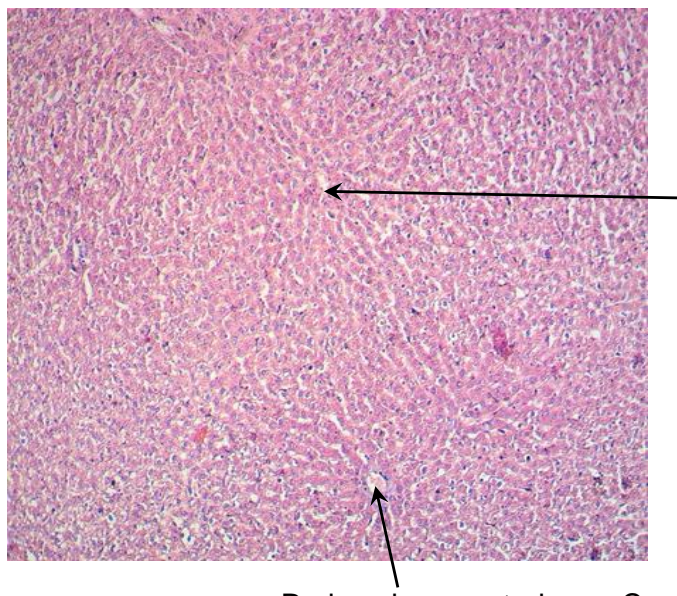

Reduced congested central vein
Plate 1b; A photo micrograph of a liver section of a rat in the group 2 showing: normal central vein normal arrangement of liver cords. The hepatocytes are seen radiating from the central vein and separated from each other by normal irregular blood sinusoids (H \& E. × 400)

\section{$2500 \mathrm{mg} / \mathrm{kg}$}

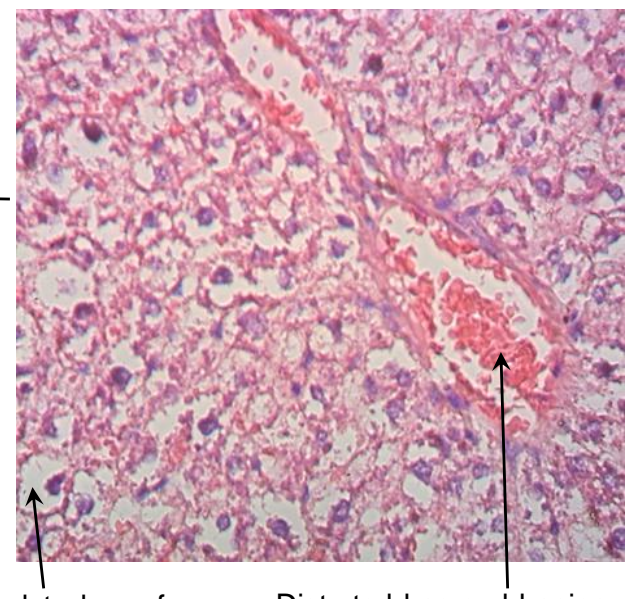

Complete loss of hepatocyte shape
Distorted haemorhhaging central vein

Plate 1c: A photo micrograph of a liver section of a rat in the group 3 there are more contorted hepatocytes and an arrower

Plate 1d: A photo micrograph of the liver section of a rat in the group 5 showing a congested and heamoragingcentral vein and a more distorted hepatocytes. Architecture of liver seriously damaged $(H \& E . \times 400)$.

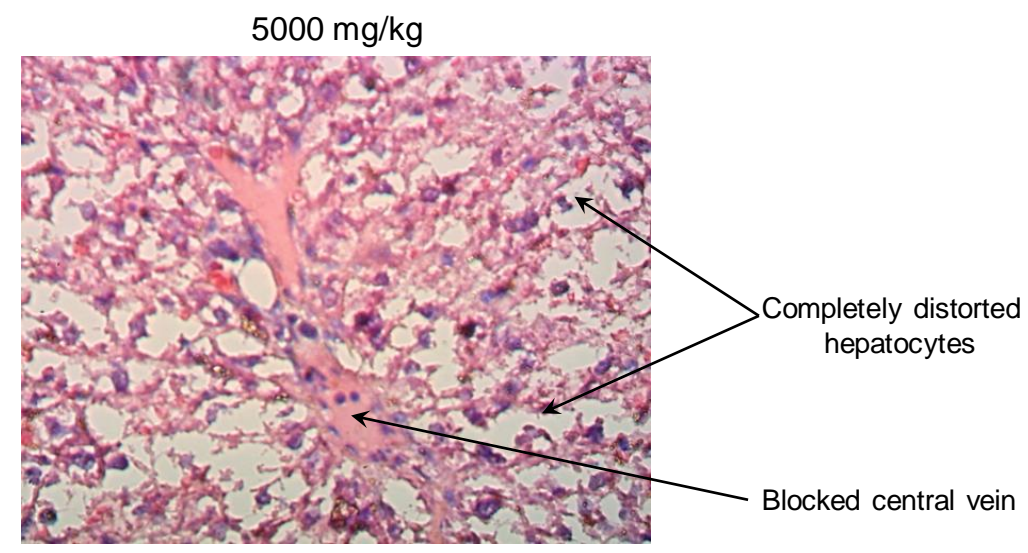

Plate 1e. Complete blockage of the central vein and the complete destruction of the architecture of the liver. (H\& E. $\times 400)$. 


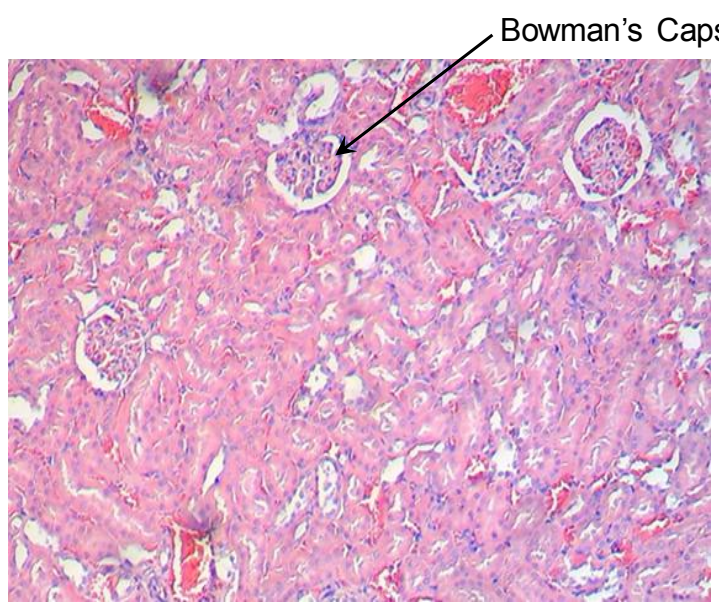

Plate 2a: A photo micrograph of a kidney section of a rat in the in the control group showing normal Bowman's capsule and glomeruli $(H \&$ E. × 400)

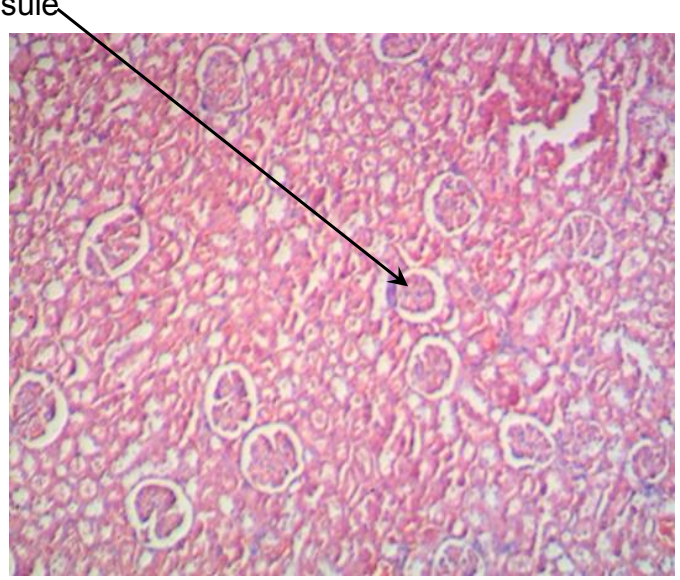

Plate 2b: A photo micrograph of a kidney section of a rat group 2 showing normal Bowman's capsule and glomerulus $(H \& E . \times 400)$.

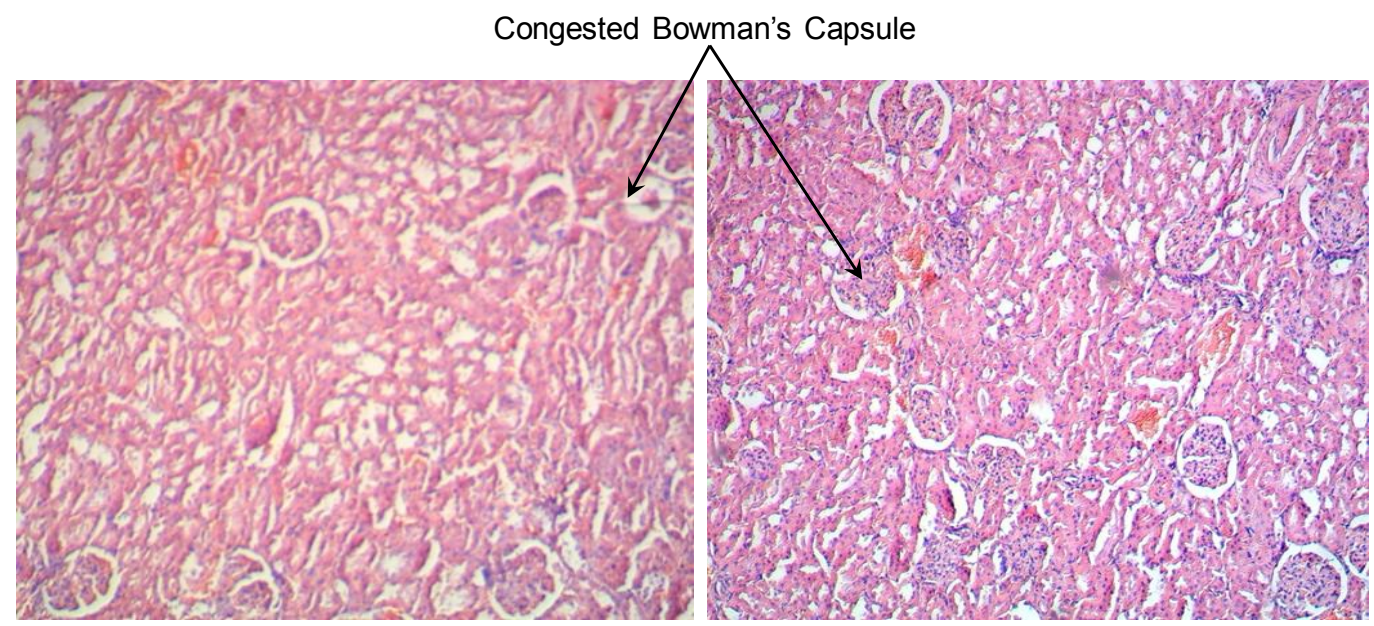

Plate 2c: A photo micrograph of a kidney section of a rat in The interlobular vein showed congestion and of Bowman's capsule and glomerulus.

Plate 2d: Distortion of architectures of the kidney in group 4 structure. mild chronic inflammatory infiltrates and haemorrhage as compared distortion

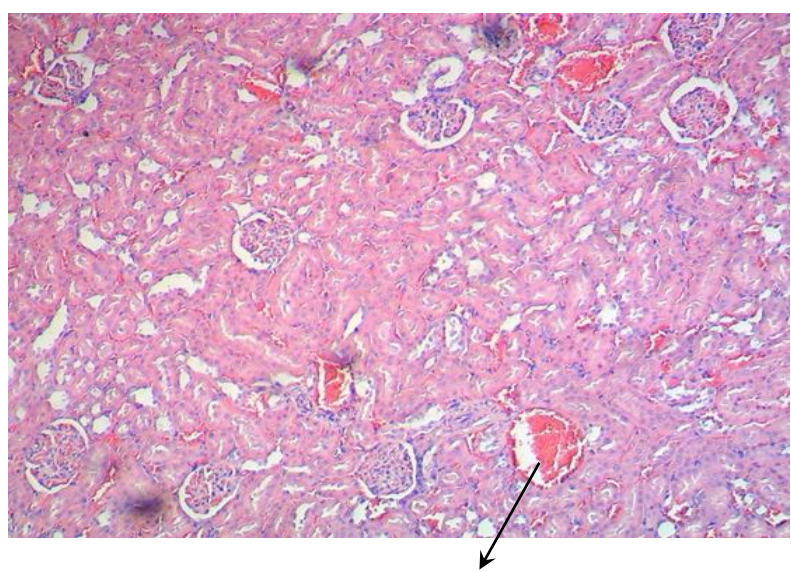

Haemorrhaging of the Bowman's capsule

Plate 2e: A photo micrograph of treated kidney section of a rat in the group 5 showing Tubular necrosis, interstitial haemorrhage and Vascular hypertrophy [H\&E x 400]. 


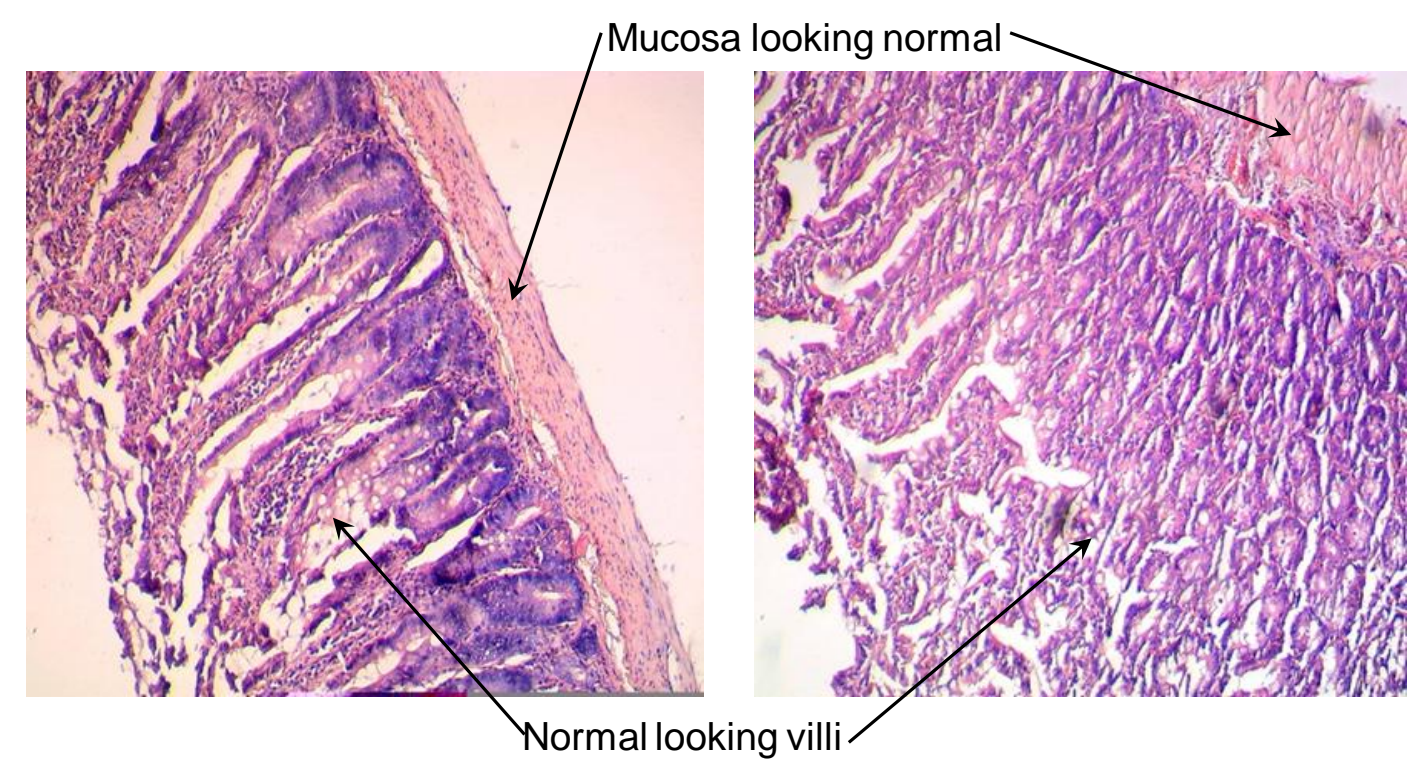

Plate 3a: A photo micrograph of a small intestine section a rat in the control group showing: normal muscularis mucosae and submucosa which appeared non-inflamed. The villi also appear normal ( $\mathrm{H} \times \&$ E. $\times 400)$.

Plate $3 \mathrm{~b}: \mathrm{A}$ photo micrograph of a small intestine section of a rat in the group 2 showing normal muscularis mucosae and submucosa which appeared non-inflamed. The villi also appear normal (Hx \& E. $\times$ 400)

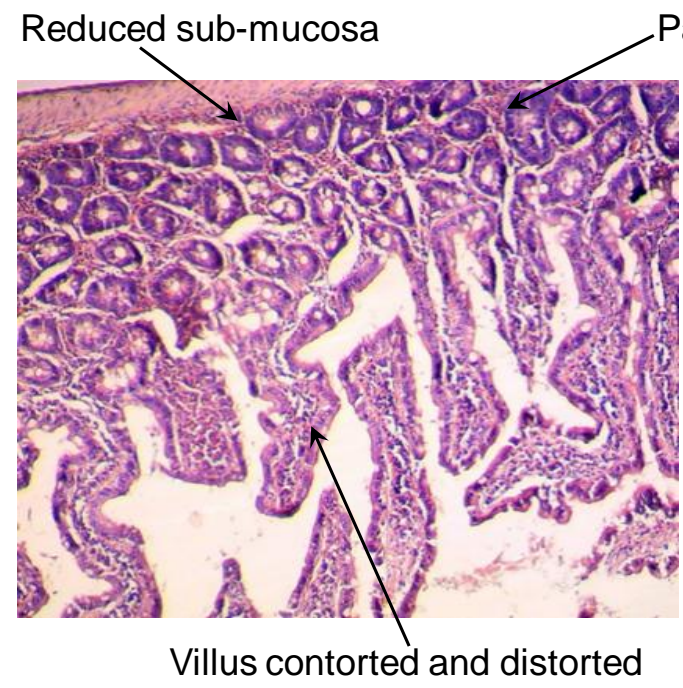

Plate 3c: A photo micrograph of a small intestine section of a rat in group 3 showing: reduction in size of submucosa, the muscularis mucosaerate had also thinned out. The villi also appear inflamed contorted and distorted $(\mathrm{Hx} \& \mathrm{E}$. $\times$ 400).

\section{Discussion}

Natural product are popular and gaining wide acceptability in Pharmacology (Pariyani et al., 2015) The general belief that the products of natural origin are safe and free from serious side effects which the synthetic drugs possess drives people towards using the natural medicines.
Paneth cell

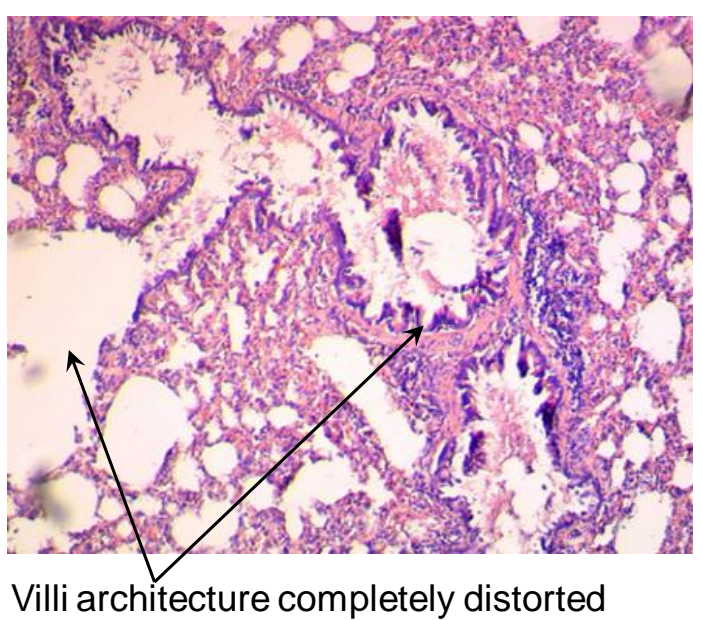

Plate 3d: A photo micrograph of the small intestine of rats in group 4 showing distortion of the mucosal layer and the destruction of the architecture of the intestine (Hx \& E. $\times 400$

However, many of the natural product formulations available in the market do not have sufficient scientific data on their safety and toxicological profile. This is of particular importance since the natural products are more often used under self-medication without a medical supervision. Hence, proper scientific knowledge on the toxicity and safe administration 
level of the natural medicines is crucial. This study revealed that the ethyl acetate extract of the stem bark of $P$. reticulatum showed considerable antibacterial properties as evidenced in Table 1 . This result is remarkable considering the high level of multiple antibiotic resistance and the high MAR indices of the test organisms as presented in Table 2.

The minimum inhibitory concentration (MIC) also proposes that the plant is effective at low concentration. The activity of the plant extract is also a function of the extraction solvent. Ethyl acetate has medium polarity and it is minimally toxic. It is also useful in the extraction of both polar and non-polar materials. Ethyl acetate is also widely used as a solvent for the extraction of compounds for cytotoxicity (Sathish and Rao, 2012).

The phytochemicals present in the plant are possibly responsible for it's antibacterial activity. Phytochemicals such as alkaloids, glycosides, steroids, phenol, tannin and saponin have rational uses and are found in varying amounts in plants. Their specific roles are to prevent diseases (Shad et al., 2014), act as antimicrobial and antioxidant (Larayetan et al., 2019). These phytochemicals have been known to be biologically active and thus partially responsible for the antimicrobial activities of plants (Nathathe and Ndip, 2015), hence their use in traditional medicine.

The monitoring of body weight is important while studying the toxicity and safety of a natural product.It hints at the physiological and metabolic status of the animals and guides against "false" observations due to nutritional abnormalities of the rats. In the current study, there was no significant loss or gain in weight between the control and treated animals ( $\mathrm{p} \geq 0.05)$. This is suggestive of the plant extract not inducing significant changes in the appetite and not exerting any deleterious effects on the general health status and metabolic growth of the rats. It was observed that the extract did not provoke any visible toxic manifestations (respiratory distress, uncoordinated muscle movements, etc.) or mortality in animals.

The assessment of the hematological parameters is important as it reveals the systemic effects caused by the administered extract. From the results, the hematological profile of all the treated rats showed no significant difference $(\mathrm{P} \geq 0.05)$ in comparison with the control group.

Several important biochemical parameters were also included in this toxicity study. The primary organs prone to the toxic effects of medicines are the kidney and liver. The kidney function parameters such as serum creatinine, urea, and total protein were determined, while the level of AST and ALT was determined to assess the liver function. The physical appearances of the rats used in the experiment suggested that the kidney and liver functions were not altered. There were no statistically significant differences in creatinine, urea, total protein, AST, and ALT levels between controls and treated animals. These findings suggest that plant extracts of $P$. reticulatum did not cause any deleterious effects on kidney and liver of the rats.

Histopathological studies were conducted on kidney, liver, intestine of sacrificed rats. Gross examination of the organs showed signs of necropsy and abnormal morphological changes. The microscopic examination of the hematoxylin eosin stained tissue sections also recorded changes as compared and distortion sometimes showing extreme damage of the organ architectures as compared with the control rats' tissues. However, the functionality of the organs even with such extreme damages and no mortality in treated rats is an indication of high level of tolerance of the rats to the substance administered.

The results obtained from this oral toxicity study suggest that extract of the stem bark of $P$. reticulatum is relatively nontoxic and the noobserved-adverse-effect level. (NOAEL) of $P$. reticulatum was determined as $5000 \mathrm{mg} / \mathrm{kg}$ body weight.

\section{Conclusion}

Clearly, the result of this research work is an indication of the usefulness of the plant as chemotherapeutic agent which agrees with its use in traditional medicine. The evidently low toxicity is an added advantage and as such the plant can be considered as a lead candidate in drug formulation against bacterial infection. 


\section{Conflict of interest statement}

Authors declare that they have no conflict of interest.

\section{References}

Artanti, N., Firmansyah, $\mathrm{T}$ and Darmawan A. (2012); Bioactive evaluation of Indonesia mistletoe (Dendrophthoe pentandra (l) miq) leaves extracts. J. Appl. Pharmaceut. Sci. 2, 2427.

Bancroft, J. D., Marilyn, G., 2002. Theory and practice of histological techniques 5 th (eds) London Edinburgh New York Philadelphia St. Louis, Sydney, Toronto. pp.231-233.

Bastos, M. L. A., Lima, M. R. F., Conserva, L. M., Andrade, V. S., Rocha, E. M., Lemos, R. P. L., 2009. Studies on the antimicrobial activity and brine shrimp toxicity of Zeyheria tuberculosia (Vell) Bur. (Bignoniaeae) extracts and their many constituents. Ann. Clin. Microbiol. Antimicrob. 8(10), 1186/1476.

De-an, G., Wan-Ying, W., Min, Y., Xuan, L., Geoffery, A. C., 2015. A holistic approach to the quality control of traditional Chinese medicines. Sciences. 347, S29-S31.

Krumperman, P. H., 1983. Multiple antibiotic resistance indexing of Escherichia coli to identify high-risk sources of fecal contamination of foods. Appl. Environ. Microbiol. 46(1), 165-170.

Larayetan, R., Ololade, Z. S., Ogunmola, O. O., Ladokun, A., 2019. Phytochemical constituents, antioxidant, cytotoxicity, antimicrobial, antitrypanosomal, and antimalarial potentials of the crude extracts of Callistemon citrinus. Evid. Based Compl. Alter. Med 2019, Article ID 5410923, 14 pages.

Nethathe, B. B., Ndip, R. N., 2011. Bioactivity of Hydnora africana on selected bacterial pathogens: Preliminary phytochemical screening. Afr. J. Microbiol. Res. 5(18), 2820-2826.

Nychas, G. J. E., Tassou, C. C., Skandamis, P., 2003. Antimicrobials from herbs and spices.
In: Roller SM (Ed.), Natural antimicrobials for the minimal processing of foods.CRC Press, Woodhead Publishers, New York. pp.176-200.

Ode, S. A., Adamu, M., Saror, D. I., 2017. Determination of haematocrit using Mindray BC-280oVet $\AA$ automated haematology analyser and microhaematocrit method: a comparative study. Sokoto J. Vet. Sci. 15(2), 62.

Odebiyi, O. O., Sofowora, E. A., 2005. Phytochemical screening of Nigerian medicinal plants IV. Lloydia. 41, 234-248.

OECD (Organisation for Economic Cooperation and Development), 1995. Repeated dose 28day oral toxicity test method guideline 407 adopted 23.03.1996. In: OECD, Guidelines for testing of chemicals. Paris: Organisation for Economic Co-Operation and Development.

Ogbu, S. H., Okechukwu, F. J., 2001. The effect of storage temperature prior to separation of plasma and serum protein. J. Med. Lab. Sci. 10, 1-4.

Pariyani, R., Ismail, S. I., Azam, A. A., Abas, A., Shaari, K., Mohd Roslan Sulaiman, M.R., 2015. Phytochemical screening and acute oral toxicity study of Java tea leaf extracts. BioMed Res. Int. 2015, Article ID 742420, 8 pages.

Perez, C., Pauli, M. and Bazerque, P. (1990) An antibiotic assay by agar well diffusion method. Acta Biol. Med. Exp. 15, 113-115.

Satish, K., Sao, B., 2012. In vitro antimicrobial activity of marine actinobacteria against multi drug resistant Staphylococcus aureus. Asian Pac. J. Trop. Biomed. 1691(12), 60230-60235.

Shad, A. A., Ahmad, S., Ullah, R., Abdel-Salam, M. N., Rehman, N. U., Hussain, H., Saeed, W., 2014. Phytochemical and biological activities of four wild medicinal plants. Scient. World J. 2014, Article ID 857363, 7 pages.

Trease, G. E., Evans, W. C., 2002. Pharmacognosy. $15^{\text {th }}$ Edn. London Publishers. pp.42-44, 221229, 246-249, 304-306.

Weigand, I., Hilpert, K., Hancock, R. E. W., 2008. Agar broth dilution methods to determine the MIC of antimicrobial substances. Nature Protocol. 3(2), 163-175.

\section{How to cite this article:}

Daniel, A. O., Temikotan, T., Fadairo, K., Ibiyemi, D. A., 2020. Toxicology studies and antibacterial activities of the ethyl acetate extract of Piliostigma reticulatum. Int. J. Curr. Res. Biosci. Plant Biol. 7(5), 24-35. doi: https://doi.org/10.20546/ijcrbp.2020.705.004 